\title{
Electrochemical Evaluation of trans-Resveratrol Levels in Red Wine Based on the Interaction between Resveratrol and Graphene
}

\author{
Lantao Liu,, Yanli Zhou, ${ }^{2,3}$ Yiyu Kang, ${ }^{1}$ Haihong Huang, ${ }^{1}$ Congming Li, ${ }^{3}$ \\ Maotian $\mathrm{Xu}^{2,3}$ and Baoxian $\mathrm{Ye}^{3}$ \\ ${ }^{1}$ Henan Engineering Laboratory of Green Synthesis for Pharmaceuticals, College of Chemistry and Chemical Engineering, \\ Shangqiu Normal University, Shangqiu 476000, China \\ ${ }^{2}$ Henan Key Laboratory of Biomolecular Recognition and Sensing, College of Chemistry and Chemical Engineering, \\ Shangqiu Normal University, Shangqiu 476000, China \\ ${ }^{3}$ College of Chemistry and Molecular Engineering, Zhengzhou University, Zhengzhou 450001, China
}

Correspondence should be addressed to Yanli Zhou; zhouyanli@mails.ucas.ac.cn and Maotian Xu; xumaotian@163.com

Received 9 March 2017; Accepted 15 June 2017; Published 27 July 2017

Academic Editor: Christos Kontoyannis

Copyright (C) 2017 Lantao Liu et al. This is an open access article distributed under the Creative Commons Attribution License, which permits unrestricted use, distribution, and reproduction in any medium, provided the original work is properly cited.

trans-Resveratrol is often considered as one of the quality standards of red wine, and the development of a sensitive and reliable method for monitoring the trans-resveratrol levels in red wine is an urgent requirement for the quality control. Here, a novel voltammetric approach was described for probing trans-resveratrol using a graphene-modified glassy carbon (GC) electrode. The proposed electrode was prepared by one-step electrodeposition of reduced graphene oxide (ERGO) at a GC electrode. Compared with the bare GC electrode, the introduced graphene film on the electrode surface dramatically improved the sensitivity of the sensor response due to the $\pi-\pi$ interaction between the graphene and trans-resveratrol. The developed sensor exhibited low detection limit of $0.2 \mu \mathrm{M}$ with wide linear range of $0.8-32 \mu \mathrm{M}$ and high stability. For the analysis of trans-resveratrol in red wine, the high antiinterference ability and the good recoveries indicated the great potential for practical applications.

\section{Introduction}

Resveratrol (3,5,4' -trihydroxystilbene), a member of the stilbene family of phenolic compounds, has been reported to have health benefits because it could provide antioxidative and carcinogenic protection, reduce platelet aggregation, and then decrease the incidence of coronary heart disease [1]. Resveratrol is present in grapes, peanuts, and mulberries, and it is noted that a large amount of phenolic compounds in skins, seeds, and pulp of grapes is partially extracted during winemaking [2]. Red wine seems to be an essential component and moderate drinking could be responsible for health-promoting properties. Phenolic compounds are related to several sensorial characteristics such as color, flavor, astringency, and hardness of red wine, and particularly transresveratrol has become one of the quality standards of red wine $[3,4]$. Therefore, the rapid, sensitive, and accurate determination of trans-resveratrol in red wine is very important for the improvement of manufacturing process, the control of storage condition, and the evaluation of nutrition value.

Due to the important physiological role and the significance of trans-resveratrol level, several analytical methods including liquid chromatography [5-11], capillary electrophoresis [12-15], fluorescent assays [16, 17], spectroscopy technique $[18,19]$, and molecularly imprinted polymer $[20$, 21] have been reported for the analysis of trans-resveratrol. The limitation of the fluorescent assays and spectroscopy technique is the substance interference from the real samples [22]. The trans-resveratrol detection by chromatographic, electrophoretic, and molecularly imprinted polymer has high sensitivity and specificity, but these methods are time-consuming and/or need expensive instruments. Electrochemical 
methods can allow for accurate and direct determination of potentials of redox-active molecules. However, electrochemical detection of trans-resveratrol using bare electrodes is difficult owing to its high overpotential and the interference of coexisting phenolic compounds in red wines. The electrochemical sensors have been designed for the trans-resveratrol detection, while some limitations including complicated fabrication process or low sensitivity still exist [23-31]. Hence, the search for reliable material for the modification on the electrode surface to determine trans-resveratrol is of considerable interest.

Among the modified materials, graphene has attracted tremendous attentions as an ideal material for electrochemistry because of its large surface area, large 2D electrical conductivity, and low cost [32]. So far, most of the graphene immobilized on electrode surface by drop-casting was synthesized by chemical reduction of graphene oxide sheets. Toxic reducing agents were needed in the chemical methods, and the preparation of the graphene-modified electrodes involved a coating process to keep their stability [33]. Recently, the modification of graphene on electrode surfaces by electrochemical methods has been certified to be a promising strategy due to its fast, simple, stable, and green nature [34]. Our group reported that a graphene film on the electrode surface was formed from graphene oxide dispersion by one-step electrodeposition, and the introduced graphene layer facilitates the electron transfer between the analyte and the electrode surface $[35,36]$. In addition, resveratrol has strong interaction with the graphene-related materials by their $\pi-\pi$ stacking [37]. In this regard, the graphene layer is expected to accumulate trans-resveratrol on the electrode surface and promote its electron transfer.

Herein, a new electrochemical sensing platform for transresveratrol detection was developed based on graphenemodified electrode prepared by one-step electrodeposition of graphene oxide. The electrochemical behavior of the transresveratrol was studied on the graphene-modified electrode. The analytical characteristics including sensitivity, detection range, and stability of this sensing system were investigated. The further determination for red wine samples was also researched to test the effectivity of the method for food quality control. This strategy for trans-resveratrol detection is advantageous in terms of its simplicity, sensitivity, high stability, and anti-interference ability.

\section{Materials and Methods}

2.1. Chemical and Reagents. Graphene oxide was obtained from graphite nanopowders (Sinopharm Chemical Reagent Co., China) by a modified Hummers method [35]. transResveratrol was purchased from Sigma-Aldrich. 0.04 M Britton-Robinson (BR) buffer solution was prepared from an acidic solution which contained $0.04 \mathrm{M} \mathrm{H}_{3} \mathrm{PO}_{4}, \mathrm{HOAc}$, and $\mathrm{H}_{3} \mathrm{BO}_{3}$ by adjusting to different $\mathrm{pH}$ using $0.2 \mathrm{M} \mathrm{NaOH}$. All other reagents were supplied by commercial suppliers and used without a filtration system. The water used was purified by a Millipore $M-Q$ purification system $(>18 \mathrm{M} \Omega$ ).

2.2. Preparation of the Graphene-Modified Electrode. Glassy carbon (GC, $3 \mathrm{~mm}$ in diameter, Shanghai $\mathrm{CH}$ Instruments,
China) surfaces were polished with $1.0,0.3$, and $0.05 \mu \mathrm{m}$ alumina powder using pure water on polishing cloths until a mirror finish was obtained. The electrodes were sonicated for $5 \mathrm{~min}$ to remove the alumina residues followed by rinsing with pure water and acetone. After polishing, 15 consecutive cycles from 0.5 to $-1.5 \mathrm{~V}$ (versus $\mathrm{Ag} / \mathrm{AgCl}$ ) were carried out on the GC electrodes in a $0.5 \mathrm{~g} \mathrm{~L}^{-1}$ graphene oxide dispersion solution containing $0.1 \mathrm{M} \mathrm{KCl}$ at a scan rate of $50 \mathrm{mV} \mathrm{s}^{-1}[35$, 36]. Thus, the electrodeposition of reduced graphene oxidemodified GC (ERGO/GC) electrodes was fabricated, and the working electrode was stored at $4^{\circ} \mathrm{C}$ in refrigerator prior to use. The surface morphologies of the modified electrodes were examined with scanning electron microscopy (SEM; Quonxe-2000, FEI).

2.3. Electrochemical Measurements. All electrochemical measurements were carried out on a CHI 660D electrochemical workstation (Shanghai CH Instruments, China). A conventional three-electrode system was used with a modified GC disk electrode, a platinum foil, and a saturated $\mathrm{Ag} / \mathrm{AgCl}$ as working electrode, counter electrode, and reference electrode, respectively. The voltammetric responses of transresveratrol on the ERGO/GC electrodes were recorded by differential pulse voltammetry (DPV) from 0 to $-0.5 \mathrm{~V}$ with a pulse amplitude of $0.005 \mathrm{~V}$ and a pulse width of $0.1 \mathrm{~s}$. Prior to each electrochemical measurement, the buffer solutions were purged with high-purity $\mathrm{N}_{2}$ gas for at least $15 \mathrm{~min}$. All electrochemical measurements were performed at room temperature.

2.4. Determination of trans-Resveratrol in Red Wine. The red wine samples (Greatwall, China) were purchased from local supermarkets. At first, $6.0 \mathrm{~mL}$ of sodium hydrogen tartrate/disodium tartrate buffer solution $(0.26 \mathrm{M})$ was added to $0.50 \mathrm{~mL}$ of red wine in a separatory funnel. The mixed solution was extracted with $5.0 \mathrm{~mL}$ of diethyl ether by shaking vigorously for $60 \mathrm{~s}$, and then the upper organic phase was separated and evaporated to dryness by a stream of $\mathrm{N}_{2}$ gas at room temperature. Finally, the residue was diluted to $10.0 \mathrm{~mL}$ using 0.04 M BR ( $\mathrm{pH} 2.0$ ) solution, and the DPV curves were recorded for the detection of trans-resveratrol in the red wine.

\section{Results and Discussion}

3.1. Characterization of the ERGO/GC Electrode. Illustrations of the preparation of the ERGO/GC electrode and the detection for trans-resveratrol were shown in Scheme 1. The formation of ERGO film on the electrode surface was directly verified by SEM characterization (Figure 1(b)). The presence of thin, aggregated, and crumpled graphene sheets associated with a wrinkled texture was observed, indicating their high surface area. To compare the charge transfer property of the GC electrode before and after the modification of ERGO, cyclic voltammetry $(\mathrm{CV})$ for $1 \mathrm{mM}\left[\mathrm{Fe}(\mathrm{CN})_{6}\right]^{3-/ 4-}$ in $0.1 \mathrm{M}$ PBS ( $\mathrm{pH}$ 7.0) was performed at the GC and ERGO/GC electrodes, as shown in Figure 1(a). Well-defined CV curves of $\left[\mathrm{Fe}(\mathrm{CN})_{6}\right]^{3-/ 4-}$ on the two electrodes were obtained, indicating nearly reversible or quasi-reversible electron-transfer 


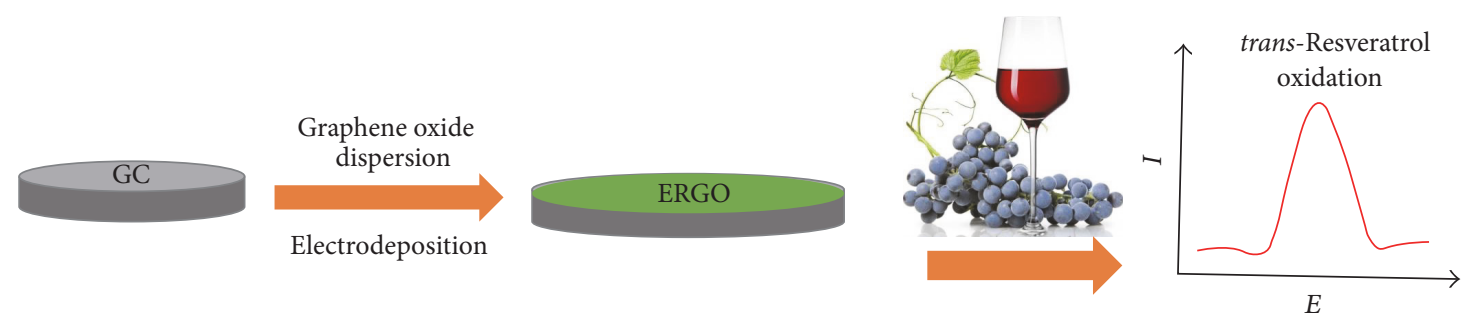

Scheme 1: Illustrations of the preparation of the ERGO/GC electrode and the detection of trans-resveratrol.

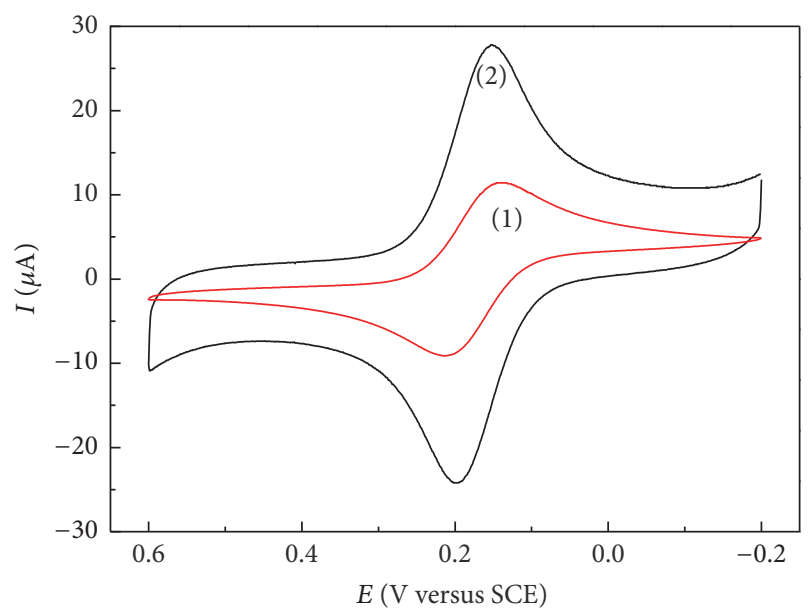

(a)

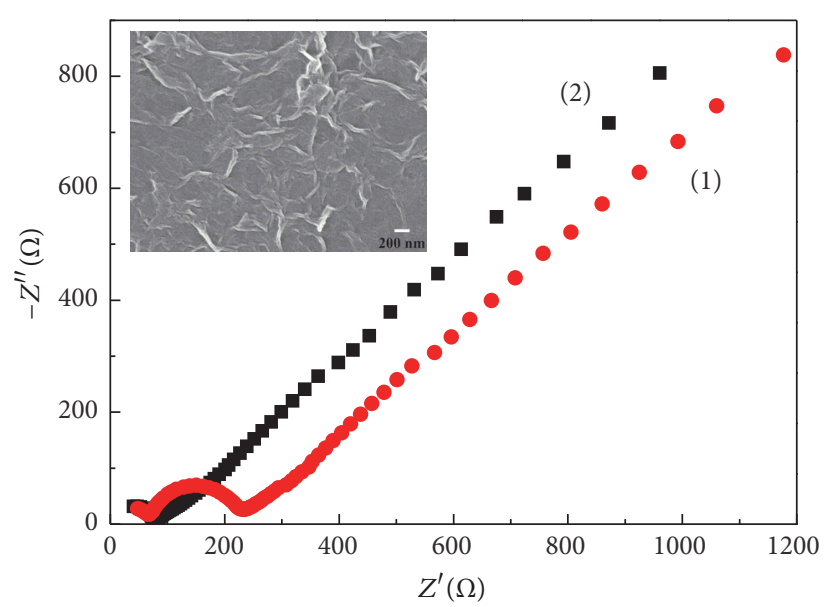

(b)

Figure 1: (a) CV curves of $1 \mathrm{mM}\left[\mathrm{Fe}(\mathrm{CN})_{6}\right]^{3-/ 4-}$ in $0.1 \mathrm{M} \mathrm{PBS}(\mathrm{pH} 7.0)$ at a scan rate of $50 \mathrm{mV} \mathrm{s}^{-1}$ and (b) Nyquist plots of $10 \mathrm{mM}\left[\mathrm{Fe}(\mathrm{CN})_{6}\right]^{3-/ 4-}$ in $0.1 \mathrm{M} \mathrm{KCl}$ from $0.1 \mathrm{MHz}$ to $0.1 \mathrm{~Hz}$ at ac amplitude of $5 \mathrm{mV}$ under open-circuit potential conditions, obtained at the GC (1) and ERGO/GC (2) electrodes. Inset of (b) is the SEM image for the ERGO/GC electrode.

kinetics for both interfaces. However, compared with GC electrode, there was an obvious increase in the cathodic and anodic current responses and a significant decrease in the potential difference $\left(\Delta E_{p}\right.$ from 73 to $48 \mathrm{mV}$ ) at the $\mathrm{ERGO} / \mathrm{GC}$ electrode. The results might be attributed to the plenty of surface area and the high electric conductivity of ERGO film presented on the surface of GC electrode.

The ERGO/GC electrode was further evaluated by electrochemical impedance spectroscopy (EIS) in $0.1 \mathrm{M} \mathrm{KCl} \mathrm{con-}$ taining $5 \mathrm{mM}\left[\mathrm{Fe}(\mathrm{CN})_{6}\right]^{3-/ 4-}$, as illustrated in Figure 1(b). The semicircle portion appearing at high frequencies corresponds to the charge transfer limiting process, and the electrontransfer resistance $\left(R_{\mathrm{et}}\right)$ could be directly measured from the semicircle diameter. At the bare GC electrode, the $R_{\text {et }}$ value could be estimated to be $76 \pm 3 \Omega$. After the modification of ERGO on the GC electrode, the $R_{\text {et }}$ values decreased nearly to zero, revealing that the addition of graphene film formed high electron conduction pathways between the electrode surface and probe owing to less oxygen on the ERGO surface. Moreover, in comparison with the chemical reduction of graphene oxide modified on the electrode surface by drop-casting, the prepared ERGO sheets possess some advantages such as (1) simplicity by one-step electrochemical deposition, (2) green nature without toxic reducing agents, (3) controllable film thickness by the electrochemical cycle number, and (4) high stability due to its poor insolubility. Therefore, the ERGO film is an ideal substrate to study the redox properties of electroactive molecules.

3.2. Voltammetric Responses of trans-Resveratrol on the $E R G O / G C$ Electrode. Figure 2 shows a comparison of CVs for trans-resveratrol obtained at the bare GC and ERGO/GC electrodes. As expected, at the ERGO/GC electrode, an oxidation peak located at $0.62 \mathrm{~V}$ for trans-resveratrol was remarkably observed. At the bare GC electrode, only a low background current was observed. The above results are attributed to the high surface area of ERGO film and the rapid electron transfer between trans-resveratrol and the modified electrode surface. Furthermore, the hydrogen-bond interactions and/or strong aromatic $\pi-\pi$ stacking between the resveratrol and graphene make the trans-resveratrol enrichment on the electrode surface. Thus, the ERGO film introduced on the electrode surface is indeed a useful addition for transresveratrol detection.

3.3. Mechanistic Studies of trans-Resveratrol Oxidation on the ERGO/GC Electrode. Figures 3 and 4 illustrate the effects of the $\mathrm{pH}$ values and scan rates in the $0.04 \mathrm{M}$ BR buffer solution for the trans-resveratrol responses at the ERGO/GC electrode, respectively. The potential of the oxidation peak 


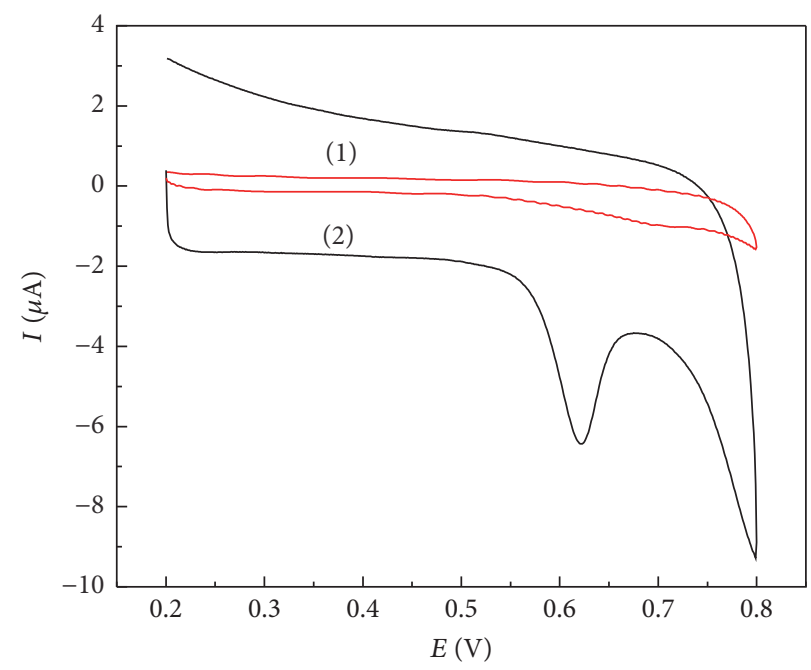

FIgURE 2: CV curves of $20 \mu \mathrm{M}$ trans-resveratrol in $0.04 \mathrm{M} \mathrm{BR}(\mathrm{pH} 2.0)$ solution at the GC (1) and ERGO/GC (2) electrodes. Scan rate: $25 \mathrm{mV} \mathrm{s}^{-1}$.

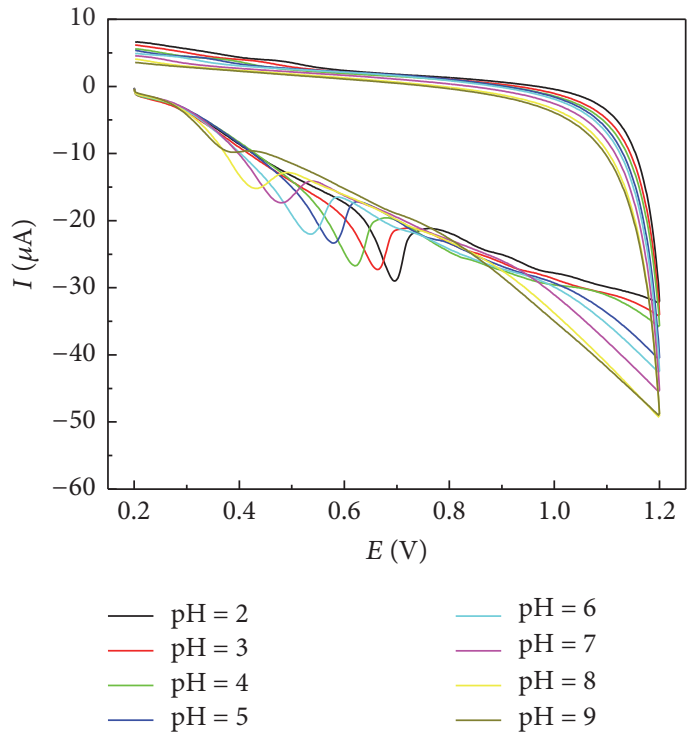

(a)

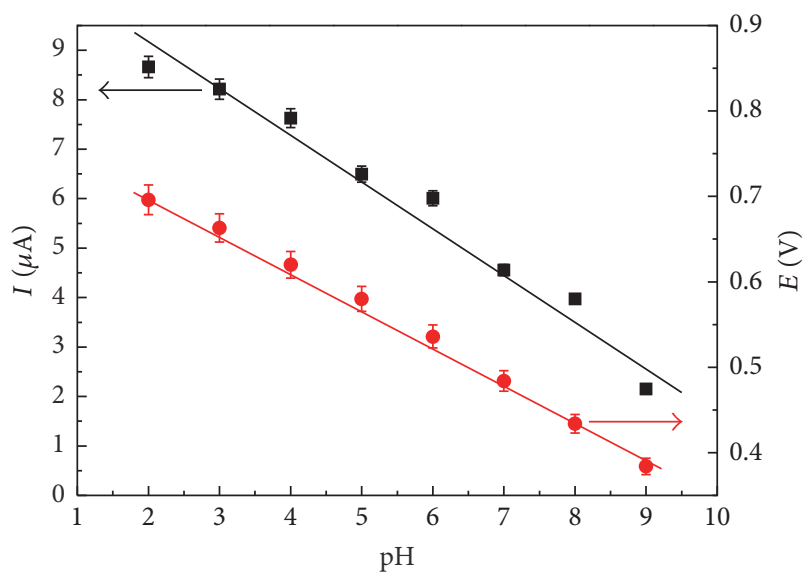

(b)

FIGURE 3: (a) CV curves of $20 \mu \mathrm{M}$ trans-resveratrol in $0.04 \mathrm{M}$ BR solution with different $\mathrm{pH}$ at the ERGO/GC electrode. Scan rate: $25 \mathrm{mV} \mathrm{s}^{-1}$. (b) Effect of $\mathrm{pH}$ value on oxidation peak current and peak potential.

shifted to more negative potentials between $\mathrm{pH} 2.0$ and 9.0 in Figure 3, demonstrating the participation of the proton transfer on the electrode surface. The peak current decreased with the increasing of $\mathrm{pH}$ value from 2.0 to 10.0 , which could be attributed to a difference in adsorption of its acidic and basic form. In consideration of buffer range, the $0.04 \mathrm{M}$ BR buffer solution ( $\mathrm{pH} 2.0$ ) was selected as the supporting electrolyte for the following studies. In Figure 4(a), the peak currents of trans-resveratrol increased with the increase of the scan rates. The peak current of trans-resveratrol exhibited linear relationship with scan rate in the range of $0.05-0.21 \mathrm{~V} \mathrm{~s}^{-1}$ (Figure 4(b)). The linear regression equation was $I_{p}=-3.21+$ $94.47 v(R=0.999)$, suggesting that the absorption-controlled behavior predominated in this process.
In Figure 4(c), the oxidation peak potential shifted to less positive values with the increase of scan rates, and a linear correlation between the peak potential and the natural logarithm of scan rate was $E_{p}=0.74+0.043 \ln v(R=0.997)$. The relationship between the oxidation peak potential and the scan rate for the irreversible electrode process obeys the following equation:

$$
E_{p}=E^{0 \prime}+\left(\frac{R T}{\alpha n_{a} F}\right) \ln \left(\frac{R T k^{0}}{\alpha n_{a} F}\right)+\left(\frac{R T}{\alpha n_{a} F}\right) \ln v,
$$

where $E^{0 \prime}$ is the formal potential, $\alpha$ is the transfer coefficient, $n_{a}$ is the number of the electrons transferred in the ratedetermining step, $k^{0}$ is the electrochemical rate constant, $R$ 


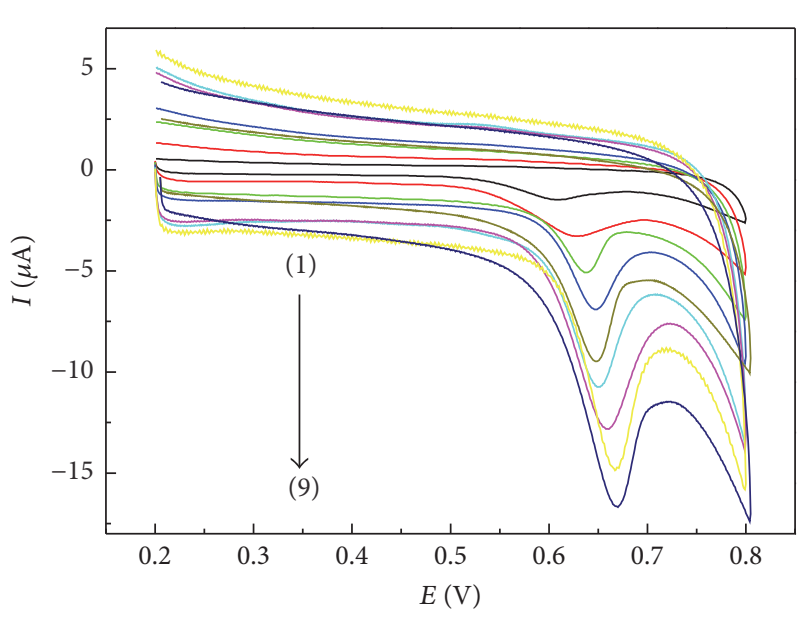

(a)

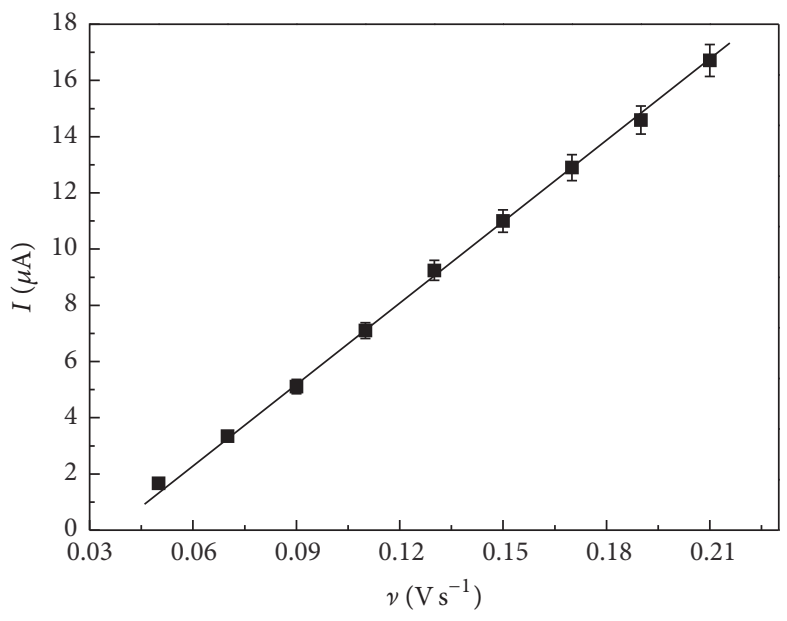

(b)

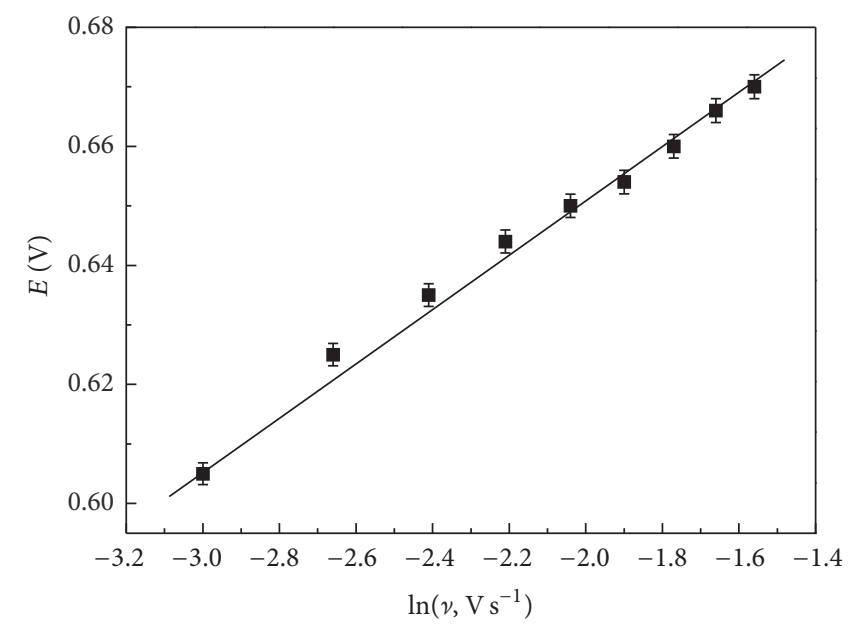

(c)

FIGURE 4: (a) CV curves of $20 \mu \mathrm{M}$ trans-resveratrol in $0.04 \mathrm{M} \mathrm{BR}$ solution (pH 2.0) at the ERGO/GC electrode with different scan rate: (1) 50, (2) 70, (3) 90, (4) 110, (5) 130, (6) 150, (7) 170, (8) 190, and (9) $210 \mathrm{mV} \mathrm{s}^{-1}$. Effect of scan rate on oxidation peak current (b) and peak potential (c).

is the gas constant, $T$ is the temperature, and $F$ is the Faraday constant. The value of $\alpha n_{a}$ was calculated to be 0.59 from the slope (0.043) of the linear correlation. The value of $\alpha$ was from 0.3 to 0.7 for most systems. Thus, assuming that $\alpha=0.5, n_{a}$ was estimated to be 1 for the oxidation of trans-resveratrol at the ERGO/GC electrode. In addition, the relationship of the oxidation peak potential and $\mathrm{pH}$ value in Figure 3(b) was in accord with the following equation: $E_{p}(V)=0.80-$ $0.045 \mathrm{pH}$. Therefore, the number of protons $(m)$ in the transresveratrol oxidation was equal to the number of $n_{a}$ according to the Nernst equation $E_{p}=E^{0}-0.059\left(m / n_{a}\right) \mathrm{pH}$. Based on the above results, the trans-resveratrol oxidation on the ERGO/GC electrode involved 1 electron and 1 proton, which was consistent with the reported electrochemical oxidation [29, 38, 39].

3.4. Quantitative Detection of trans-Resveratrol. The sensitivity of the ERGO/GC electrode was evaluated using a typical voltammetric response after the addition of successive aliquots of trans-resveratrol to the $0.04 \mathrm{M}$ BR buffer solution ( $\mathrm{pH}$ 2.0), as shown in Figure 5. The oxidation peak current of trans-resveratrol at the ERGO/GC electrode kept on increasing with the increasing concentration of trans-resveratrol under identical conditions. In the inset of Figure 5, the calibration of the ERGO/GC electrode to trans-resveratrol illustrated that $I_{p}$ was proportional to the concentration of trans-resveratrol. The response to trans-resveratrol was linear in the range from $0.8 \mu \mathrm{M}$ to $32 \mu \mathrm{M}(R=0.998)$, and a sensitivity of $0.1 \mu \mathrm{A} \mu \mathrm{M}^{-1}$ could be calculated from the slope of the linear range. The detection limit was $0.2 \mu \mathrm{M}$ at a signal-tonoise ratio of 3 , which was lower than or comparable to those obtained by other electrochemical sensors [23-31], liquid chromatography [5-11], capillary electrophoresis [12-15], fluorescent assays $[16,17]$, spectroscopy technique $[18,19]$, and molecularly imprinted polymer $[20,21]$. The low detection limit could be according to the electron conduction pathways and high surface area of the graphene film and its strong interaction with trans-resveratrol. Furthermore, the detection 


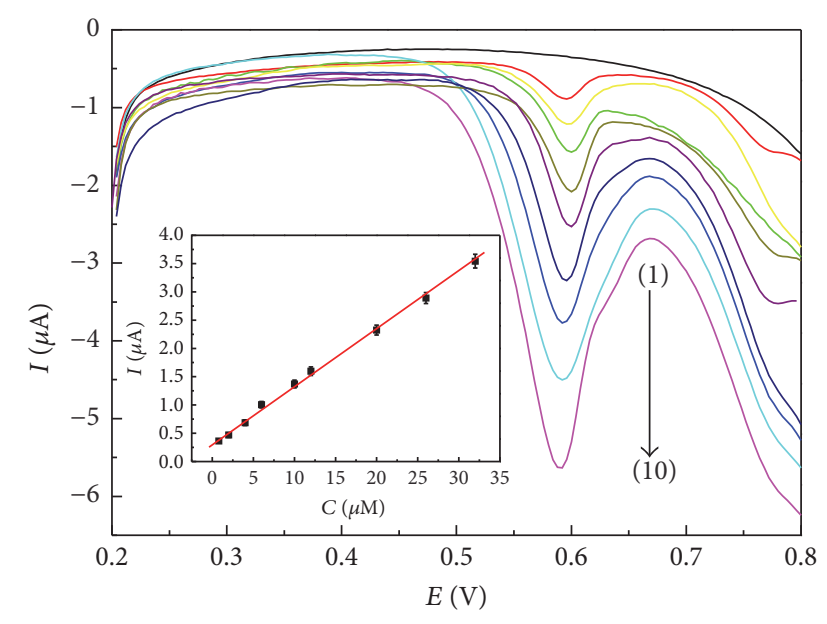

FIGURE 5: DPV curves at the ERGO/GC electrode for an increasing concentration of trans-resveratrol in the $0.04 \mathrm{M}$ BR buffer solution (pH 2.0): (1) 0, (2) 0.8, (3) 2, (4) 4, (5) 6, (6) 10, (7) 12, (8) 20, (9) 26, and (10) $32 \mu \mathrm{M}$. Inset shows the calibration curve of oxidation peak current versus concentration.

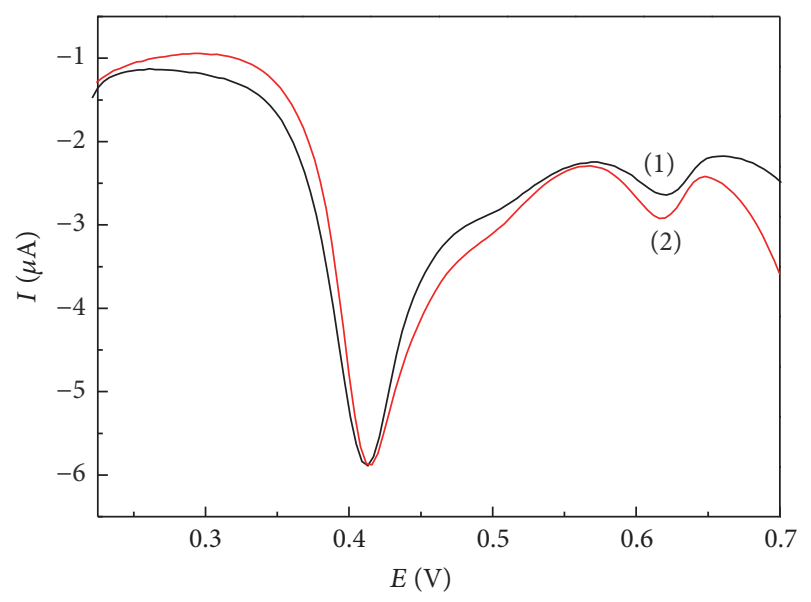

FIGURE 6: DPV curves of the ERGO/GC electrode before and after the addition of $5 \mu \mathrm{M}$ trans-resveratrol for the red wine sample.

limit of trans-resveratrol also met the requirement for evaluation of the trans-resveratrol level in red wine (several $\mathrm{mg} \mathrm{L}^{-1}$ ).

The stabilities including repeatability, reproducibility, and long-term stability of the ERGO/GC electrode for the transresveratrol detection were assessed by the measurement of the response to $20 \mu \mathrm{M}$ trans-resveratrol in $0.04 \mathrm{M} \mathrm{BR}$ (pH 2.0) solution. 9 successive modifications of ERGO at the same GC electrode were investigated for repeatability under the same conditions, and the relative standard deviation (RSD) was $6.59 \% .5$ different ERGO/GC electrodes were studied for the reproducibility, and the RSD was $8.71 \%$. For purpose of evaluation of the long-term stability, the developed modified electrode was stored in $0.04 \mathrm{M} \mathrm{BR}(\mathrm{pH} 2.0)$ solution at $4^{\circ} \mathrm{C}$ and it retained $95.6 \%$ original voltammetric response even after one month. Consequently, the above results revealed the excellent stability of the modified ERGO film due to its poor insolubility.
3.5. Analysis of trans-Resveratrol in Red Wine. To verify the practicality of the developed method, the red wine residue was diluted using $0.04 \mathrm{M} \mathrm{BR}(\mathrm{pH} 2.0$ ) solution and then was analyzed for the evaluation of the trans-resveratrol level at the ERGO/GC electrode. As shown in Figure 6, the oxidation peak of trans-resveratrol was observed and a big peak at $0.43 \mathrm{~V}$ also appeared owing to other polyphenol substrates in the red wine. The measured trans-resveratrol concentration of the wine was $7.90 \mu \mathrm{M}$. After the addition of $5 \mu \mathrm{M}$ transresveratrol in the wine sample, the recovery was $4.9 \mu \mathrm{M}$ and the recovery rate was $98 \%$. The above data represented average values of five measurements, and the RSD was 7.3\%. Thus, the simplicity, high sensitivity, and anti-interference ability of the ERGO/GC electrode may bring it as the transresveratrol detector in the food analysis.

\section{Conclusion}

In brief, a simple and highly enhanced sensing platform based on the ERGO film was established for the trans-resveratrol detection by DPV. Compared with the reported methods for trans-resveratrol detection, the proposed voltammetric sensor provided important advantages as follows. (i) Preparation of the graphene film by one-step electrochemical deposition was a simple, efficient, and green technique. (ii) The sensor was sensitive for trans-resveratrol detection due to the strong aromatic $\pi-\pi$ stacking between resveratrol and graphene. (iii) High stability was obtained because of the stability of the graphene coating. (iv) The efficient interaction between transresveratrol and the graphene film endowed the excellent antiinterference ability in real samples. Therefore, the proposed electrochemical strategy provided valuable information for evaluation of trans-resveratrol levels in red wines. The efficient evaluation should get us closer to finding a way for improvement of manufacturing process, the storage control, and the nutrition evaluation of red wines.

\section{Conflicts of Interest}

The authors declare that they have no conflicts of interest.

\section{Acknowledgments}

This work was supported by grants from the National Natural Science Foundation of China (Grants nos. 21675109, 21572126, and 21475084), China Postdoctoral Science Foundation (2016M590684), Program for Science \& Technology Innovation Talents in Universities of Henan Province (16HASTIT005 and 14HASTIT016), Natural Science Foundation of Henan Province (162300410209), and Innovation Scientists and Technicians Troop Construction Projects of Henan Province (no. 41, C20150030).

\section{References}

[1] M. H. Keylor, B. S. Matsuura, and C. R. J. Stephenson, "Chemistry and biology of resveratrol-derived natural products," Chemical Reviews, vol. 115, no. 17, pp. 8976-9027, 2015.

[2] M. I. Fernández-Mar, R. Mateos, M. C. García-Parrilla, B. Puertas, and E. Cantos-Villar, "Bioactive compounds in wine: 
Resveratrol, hydroxytyrosol and melatonin: A review, Food Chemistry, vol. 130, no. 4, pp. 797-813, 2012.

[3] R. F. Guerrero, M. C. Garcia-Parrilla, B. Puertas, and E. CantosVillar, "Wine, resveratrol and health: a review," Natural Product Communications, vol. 4, no. 5, pp. 635-658, 2009.

[4] S. Zhang, H. Bai, J. Pi, P. Yang, and J. Cai, "Label-free quartz crystal microbalance with dissipation monitoring of resveratrol effect on mechanical changes and folate receptor expression levels of living MCF-7 cells: A model for screening of drugs," Analytical Chemistry, vol. 87, no. 9, pp. 4797-4805, 2015.

[5] T. Stark, N. Wollmann, S. Lösch, and T. Hofmann, "Quantitation of resveratrol in red wines by means of stable isotope dilution analysis-ultra-performance liquid chromatography-quantime-of-flight mass spectrometry and cross validation," Analytical Chemistry, vol. 83, no. 9, pp. 3398-3405, 2011.

[6] I. Kolouchová-Hanzlíková, K. Melzoch, V. Filip, and J. Šmidrkal, "Rapid method for resveratrol determination by HPLC with electrochemical and UV detections in wines," Food Chemistry, vol. 87, no. 1, pp. 151-158, 2004.

[7] Q. J. Kong, X. Y. Ren, N. Hu, C. R. Sun, and Y. J. Pan, "Identification of isomers of resveratrol dimer and their analogues from wine grapes by HPLC/MSn and HPLC/DAD-UV," Food Chemistry, vol. 127, no. 2, pp. 727-734, 2011.

[8] L. Němcová, J. Zima, J. Barek, and D. Janovská, “Determination of resveratrol in grains, hulls and leaves of common and tartary buckwheat by HPLC with electrochemical detection at carbon paste electrode," Food Chemistry, vol. 126, no. 1, pp. 374-378, 2011.

[9] A. R. Neves, S. Reis, and M. A. Segundo, "Development and validation of a HPLC method using a monolithic column for quantification of trans-resveratrol in lipid nanoparticles for intestinal permeability studies," Journal of Agricultural and Food Chemistry, vol. 63, no. 12, pp. 3114-3120, 2015.

[10] L. Paulo, F. Domingues, J. A. Queiroz, and E. Gallardo, "Development and validation of an analytical method for the determination of trans - And cis -resveratrol in wine: Analysis of its contents in 186 Portuguese red wines," Journal of Agricultural and Food Chemistry, vol. 59, no. 6, pp. 2157-2168, 2011.

[11] Y. Lu, Q. Shen, and Z. Dai, "Multiwalled carbon nanotubes as sorbent for online solid-phase extraction of resveratrol in red wines prior to fused-core c18-based ultrahigh-performance liquid chromatography-tandem mass spectrometry quantification," Journal of Agricultural and Food Chemistry, vol. 59, no. 1, pp. 70-77, 2011.

[12] L. Gao, Q. Chu, and J. Ye, "Determination of trans-Resveratrol in wines, herbs and health food by capillary electrophoresis with electrochemical detection," Food Chemistry, vol. 78, no. 2, pp. 255-260, 2002.

[13] J. J. Berzas Nevado, A. M. Contento Salcedo, and G. Castañeda Peñalvo, "Simultaneous determination of cis- and trans-resveratrol in wines by capillary zone electrophoresis," Analyst, vol. 124, no. 1, pp. 61-66, 1999.

[14] Z. Dobiáová, J. Pazourek, and J. Havel, "Simultaneous determination of trans-resveratrol and sorbic acid in wine by capillary zone electrophoresis," Electrophoresis, vol. 23, no. 2, pp. 263-267, 2002.

[15] X. Gu, L. Creasy, A. Kester, and M. Zeece, "Capillary electrophoretic determination of resveratrol in wines," Journal of Agricultural and Food Chemistry, vol. 47, no. 8, pp. 3223-3227, 1999.
[16] T. G. Díaz, I. D. Merás, and D. A. Rodríguez, “Determination of resveratrol in wine by photochemically induced secondderivative fluorescence coupled with liquid-liquid extraction," Analytical and Bioanalytical Chemistry, vol. 387, no. 6, pp. 19992007, 2007.

[17] M. D. P. Godoy-Caballero, D. Airado-Rodríguez, I. DuránMerás, and T. Galeano-Díaz, "Sensitized synchronous fluorimetric determination of trans-resveratrol and trans-piceid in red wine based on their immobilization on nylon membranes," Talanta, vol. 82, no. 5, pp. 1733-1741, 2010.

[18] J. M. Orea, C. Montero, J. B. Jiménez, and A. González Ureña, "Analysis of trans-resveratrol by laser desorption coupled with resonant ionization spectrometry. Application to transresveratrol content in vine leaves and grape skin," Analytical Chemistry, vol. 73, no. 24, pp. 5921-5929, 2001.

[19] L. Camont, C. H. Cottart, Y. Rhayem et al., "Simple spectrophotometric assessment of the trans-/cis-resveratrol ratio in aqueous solutions," Analytica Chimica Acta, vol. 634, no. 1, pp. 121-128, 2009.

[20] S. N. N. S. Hashim, L. J. Schwarz, R. I. Boysen, Y. Yang, B. Danylec, and M. T. W. Hearn, "Rapid solid-phase extraction and analysis of resveratrol and other polyphenols in red wine," Journal of Chromatography A, vol. 1313, pp. 284-290, 2013.

[21] M. A. Euterpio, I. Pagano, A. L. Piccinelli, L. Rastrelli, and C. Crescenzi, "Development and validation of a method for the determination of (E)-resveratrol and related phenolic compounds in beverages using molecularly imprinted solid phase extraction," Journal of Agricultural and Food Chemistry, vol. 61, no. 8, pp. 1640-1645, 2013.

[22] E. Moretón-Lamas, M. Lago-Crespo, M. Lage-Yusty, and J. López-Hernández, "Comparison of methods for analysis of resveratrol in dietary vegetable supplements," Food Chemistry, vol. 224, pp. 219-223, 2017.

[23] D. Airado-Rodríguez, T. Galeano-Díaz, and I. Durán-Merás, "Determination of trans-resveratrol in red wine by adsorptive stripping square-wave voltammetry with medium exchange," Food Chemistry, vol. 122, no. 4, pp. 1320-1326, 2010.

[24] A. M. Granero, H. Fernández, E. Agostini, and M. A. Zón, “An amperometric biosensor for trans-resveratrol determination in aqueous solutions by means of carbon paste electrodes modified with peroxidase basic isoenzymes from Brassica napus," Electroanalysis, vol. 20, no. 8, pp. 858-864, 2008.

[25] H. Y. Xiang and W. G. Li, "Electrochemical sensor for transresveratrol determination based on indium tin oxide electrode modified with molecularly imprinted self-assembled films," Electroanalysis, vol. 21, no. 10, pp. 1207-1210, 2009.

[26] G. Fu-Chun, H. De-Si, C. Zhong, T. Shu-Zhen, and T. Ya-Fei, "An amperometric enzyme-linked immunosensor using resveratrol as the substrates for horseradish peroxidase for brucella melitensis antibody assay," Chinese Journal of Analytical Chemistry, vol. 35, no. 12, pp. 1783-1786, 2007.

[27] W. Huang, S. Luo, D. Zhou, S. Zhang, and K. Wu, "Electrochemical determination of resveratrol using multi-walled carbon nanotubes-modified glassy carbon electrode," Nanoscience and Nanotechnology Letters, vol. 5, no. 3, pp. 367-371, 2013.

[28] S. M. Mugo, B. J. Edmunds, D. J. Berg, and N. K. Gill, "An integrated carbon entrapped molecularly imprinted polymer (MIP) electrode for voltammetric detection of resveratrol in wine," Analytical Methods, vol. 7, no. 21, pp. 9092-9099, 2015.

[29] J.-X. Liu, Y.-J. Wu, F. Wang, L. Gao, and B.-X. Ye, "Adsorptive voltammetric behaviors of resveratrol at graphite electrode and 
its determination in tablet dosage form," Journal of the Chinese Chemical Society, vol. 55, no. 2, pp. 264-270, 2008.

[30] Z. Zhang, Y. Hu, H. Zhang, J. Cao, and S. Yao, "Novel layerby-layer assembly multi-walled carbon nanotube/resveratrol imprinted sol-gel electrochemical sensor," Acta Chimica Sinica, vol. 68, no. 5, pp. 431-436, 2010.

[31] B. Pekec, A. Oberreiter, S. Hauser, K. Kalcher, and A. Ortner, "Electrochemical sensor based on a cyclodextrin modified carbon paste electrode for Trans-resveratrol analysis," International Journal of Electrochemical Science, vol. 7, no. 5, pp. 4089-4098, 2012.

[32] M. J. Allen, V. C. Tung, and R. B. Kaner, "Honeycomb carbon: a review of graphene," Chemical Reviews, vol. 110, no. 1, pp. 132$145,2010$.

[33] Y. Liu, X. Dong, and P. Chen, "Biological and chemical sensors based on graphene materials," Chemical Society Reviews, vol. 41, no. 6, pp. 2283-2307, 2012.

[34] A.-M. J. Haque, H. Park, D. Sung, S. Jon, S.-Y. Choi, and K. Kim, "An electrochemically reduced graphene oxide-based electrochemical immunosensing platform for ultrasensitive antigen detection," Analytical Chemistry, vol. 84, no. 4, pp. 1871-1878, 2012.

[35] Y. Zhou, H. Dong, L. Liu, J. Liu, and M. Xu, "A novel potentiometric sensor based on a poly(anilineboronic acid)/graphene modified electrode for probing sialic acid through boronic aciddiol recognition," Biosensors and Bioelectronics, vol. 60, pp. 231236, 2014.

[36] Y. Zhou, H. Dong, L. Liu, Y. Hao, Z. Chang, and M. Xu, "Fabrication of electrochemical interface based on boronic acid-modified pyrroloquinoline quinine/reduced graphene oxide composites for voltammetric determination of glycated hemoglobin," Biosensors and Bioelectronics, vol. 64, pp. 442-448, 2014.

[37] X.-P. He, Q. Deng, L. Cai et al., "Fluorogenic resveratrolconfined graphene oxide for economic and rapid detection of Alzheimer's disease," ACS Applied Materials and Interfaces, vol. 6, no. 8, pp. 5379-5382, 2014.

[38] L. Gao, X. Wei, F. Wang, and B. Zhang, "Electrochemical behaviors of resveratrol and its interaction with DNA," Journal of the Chinese Chemical Society, vol. 61, no. 10, pp. 1141-1146, 2014.

[39] O. Corduneanu, P. Janeiro, and A. M. O. Brett, "On the electrochemical oxidation of resveratrol," Electroanalysis, vol. 18, no. 8, pp. 757-762, 2006. 

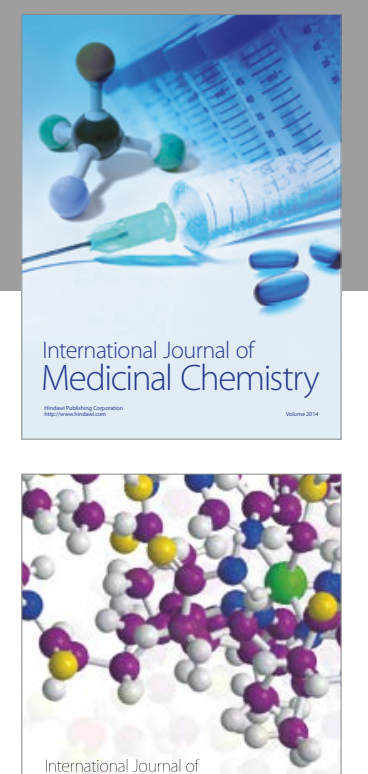

Carbohydrate Chemistry

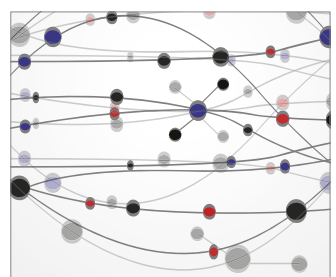

The Scientific World Journal
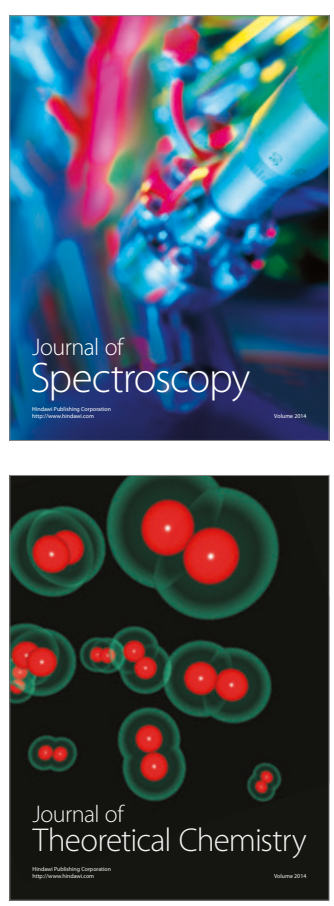
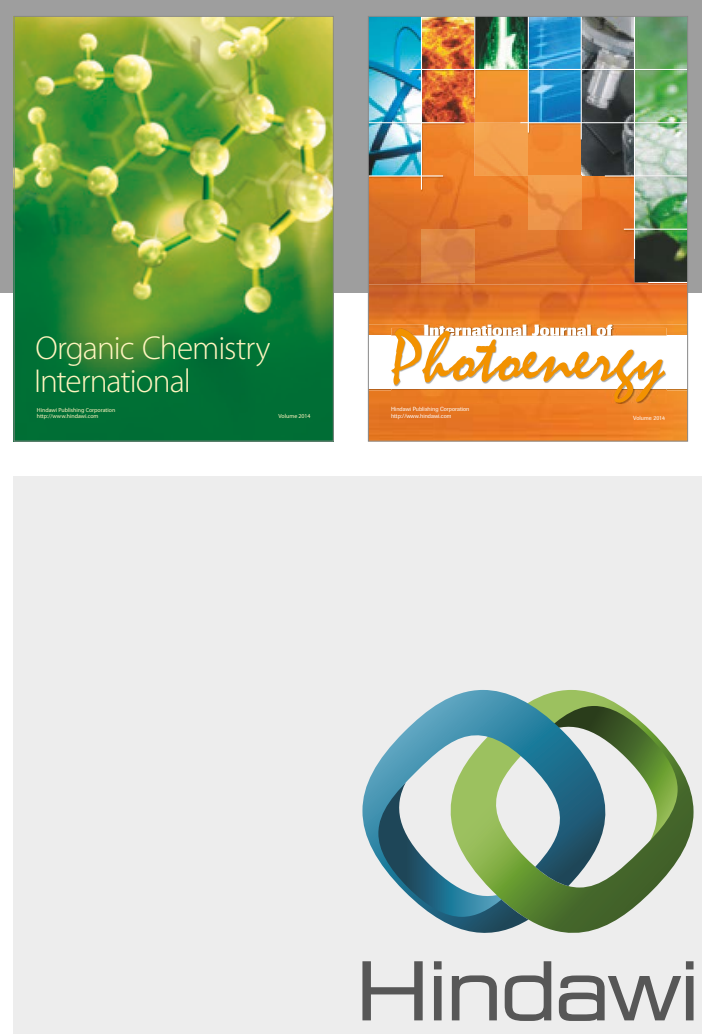

Submit your manuscripts at

https://www.hindawi.com

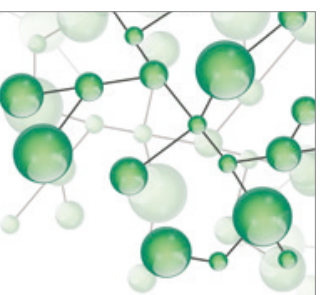

International Journal of

Inorganic Chemistry

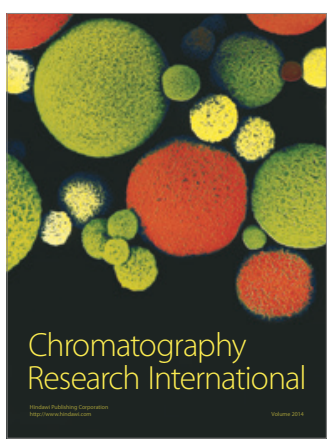

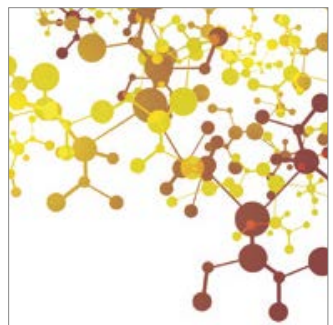

Applied Chemistry
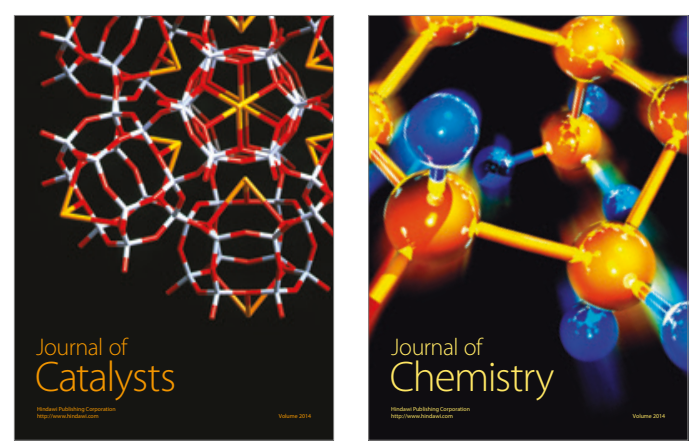
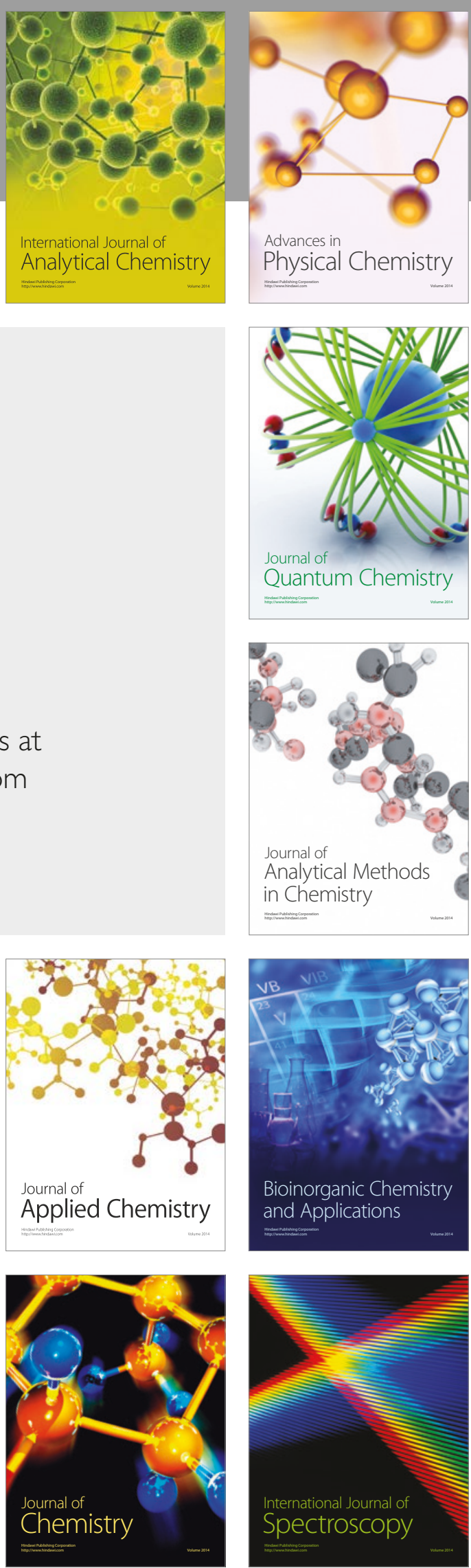